\title{
Implementation of BAT and BEP to Reduce Dioxins and Furans Emissions for Environmental Protection
}

\author{
Anahit Aleksandryan', Artak Khachatryan², Roman Prokeš ${ }^{3}$, Petra Přibylováa ${ }^{3}$, Kateřina Šebková3 \\ ${ }^{1}$ Ministry of Nature Protection of the Republic of Armenia \\ Yerevan, Republic of Armenia, 0010 \\ anahit.aleksandryan@mnp.am \\ ${ }^{2}$ Environmental Monitoring and Information Center SNCO \\ Yerevan, 0025, Republic of Armenia \\ ${ }^{3}$ RECETOX, Masaryk University \\ Brno, Czech Republic
}

\section{Extended Abstract}

Open burning covers a wide range of different uncontrolled waste combustion practices, including dump fires, pit burning, fires on plain soil and barrel burning. Open burning is the cheapest, easiest, most sanitary means of volume reduction and disposal of combustible materials in many countries.

The low temperature burning and smouldering conditions typical of open burning promote formation of many toxic chemicals, including polychlorinated dibenzo-p-dioxins (PCDDs) and dibenzofuranes (PCDFs).

The compounds produced from sources of open burning can travel long distances and deposit on soil, plants, and in water. The remaining ash in the burn pile also contains pollutants, which can spread into the soil and water.

In order to reduce releases of unintentionally produced persistent organic pollutants, including PCDDs/PCDFs, from open burning sources Best Available Techniques (BAT) and Best Environmental Practice (BEP) was implemented at the pilot site in Ararat (Republic of Armenia).

Materials and Methods. For PCDDs/PCDFs determination passive sampling was arranged and done using: passive samplers installed at the selected site of Ararat urban landfill before renovation works and development of appropriate landfill infrastructure.

Two main types of activities were undertaken:

- site and waste generation assessment;

- collection of samples for the evaluation of the environmental situation (monitoring campaigns).

The samples $(\mathrm{n}=8)$ were analyzed for PCDD/PCDFs at the laboratory of RECETOX (Masaryk University, Brno, Czech Republic) as an external laboratory. The entire procedure was executed in accordance to SOP described in the "Methodology of passive air sampling" provided by the RECETOX.

Results. The following observations were done while investigating the obtained results of passive sampling of soil:

- PCDDs were identified in 3 out of 5 soil samples

- PCDFs were identified in all 5 soil samples

- Variation of $\sum$ PCDD is in the range of $0.846-2.5 \mathrm{ng} / \mathrm{g}$ of dry matter

- Variation of $\sum \mathrm{PCDF}$ is in the range of $0.376-1.274 \mathrm{ng} / \mathrm{g}$ of dry matter

- $\sum$ PCDF Tetra + Penta is in the range of $69 \%-93 \%$

- $\sum$ PCDD Tetra + Penta is in the range of $33 \%-44 \%$.

Conclusions. The concentration of both PCDDs/PCDFs in PUFs is increasing trend from the first towards the fourth sampler. As far as the comparison between previous and current monitoring campaigns is concerned, following correlations were found:

- in $87,5 \%$ of all previous soil samples $\sum$ PCBs $\underline{\text { Tetra }+ \text { Penta }}$ was in the range of $\mathbf{8 1 \% - 9 5 . 3 \%}$

- in $100 \%$ of all current soil samples $\sum$ PCDF $\underline{\text { Tetra }+ \text { Penta }}$ is in the range of $69 \%-93 \%$. 
Recommendations. It is highly recommended to continue the monitoring campaign, take more samples in order to reveal distribution of contamination, especially in zones adjacent to agricultural lands. After the renovation works at the above mentioned site, monitoring campaign will be repeated. 